\title{
Frequency spectra of the cries of normal infants and those with Down's Syndrome'
}

VINCENT R. FISICHELLI AND SAMUEL KARELITZ ${ }^{2}$

HUNTER COLLEGE AND LONG ISLAND JEWISH HOSPITAL

Samples of tape recorded crying obtained from four male mongoloid infants six months of age, and four normal infants matched for age and sex were fed into the Panoramic Sonic Analyzer in order to survey the frequency (c.p.s.) content of the cries. While the frequency ranges did not differ for the two groups, the cries of the normal infants were richer in spectral content, more active, less variable in sound level and more homogeneous as a group than those of the mongoloid infants.

Experimental efforts now in progress at the Long Island Jewish Hospital to determine whether the crying of normal infants is different from that of infants suffering from brain damage employ a variety of approaches including (a) threshold and latency determinations, (b) volume-unit graphic analysis, (c) auditory identification and (d) phonetic content (Karelitz et al, 1960, 1962; Fisichelli et al, 1961, 1963, 1966). The present study is a further effort to differentiate between normal and brain damaged infants.

\section{Subjects}

The tape recordings analyzed in this study were selected from a library of tape recordings at the Long Island Jewish Hospital on the basis of age and sex: all six months of age, male, four normal and four infants with Down's syndrome. When more than one infant qualified, final choice was random. The infants had been made to cry by flicking the sole of the foot with the experimenter's finger. Their cries were recorded on an Ampex 601 (Electrovoice microphone 666).

\section{Apparatus and Procedure}

The spectral surveyor was a Panoramic Sonic Analyzer (Model LP-1a S/N). This instrument differs from spectral analyzers used in earlier studies of speech (Koenig et al, 1946, Potter \& Kopp, 1947; Winitz, 1960) in several respects. It provides a $10 \mathrm{~g}$ sweep from 40 to $20,000 \mathrm{cps}$ and intensity is read directly on an ordinate $\log \mathrm{dB}$ scale (linear scales available). The Panoramic model does not preserve the time scale, which is the abscissa in the usual analyzer, nor does it provide the graphic pattern for Formant analysis, but it has a sweep time of $1 \mathrm{sec}$. which permits the analysis of indefinitely long samples of sound without regard for the length of the permanent graphic record.

Since the shortest sample of continuous crying was 30 sec., it was decided in advance of analysis to scan each sample 30 times. Four sec. leeway at the beginning and at the end of the sample insured that the leader tape had been cleared and that sound was entering the analyzer; thus there were 22 sweeps of each sample. Immediately before the actual test runs were made the Sonic Analyzer was checked for calibration.

\section{Results and Discussion}

Each of the spectrograms presented in Fig. 1 show the cumulative record for 22 spectral sweeps. Inspection of the records reveals differences between the normal and the mongoloid cries. Typical of the cries of normal infants is a white rectangular cascade ranging from approximately 400 to $8000 \mathrm{cps}$. The cries of nor-

CRY SPECTROGRAMS OF

MALE INFANTS, 6 MONTHS OF AGE

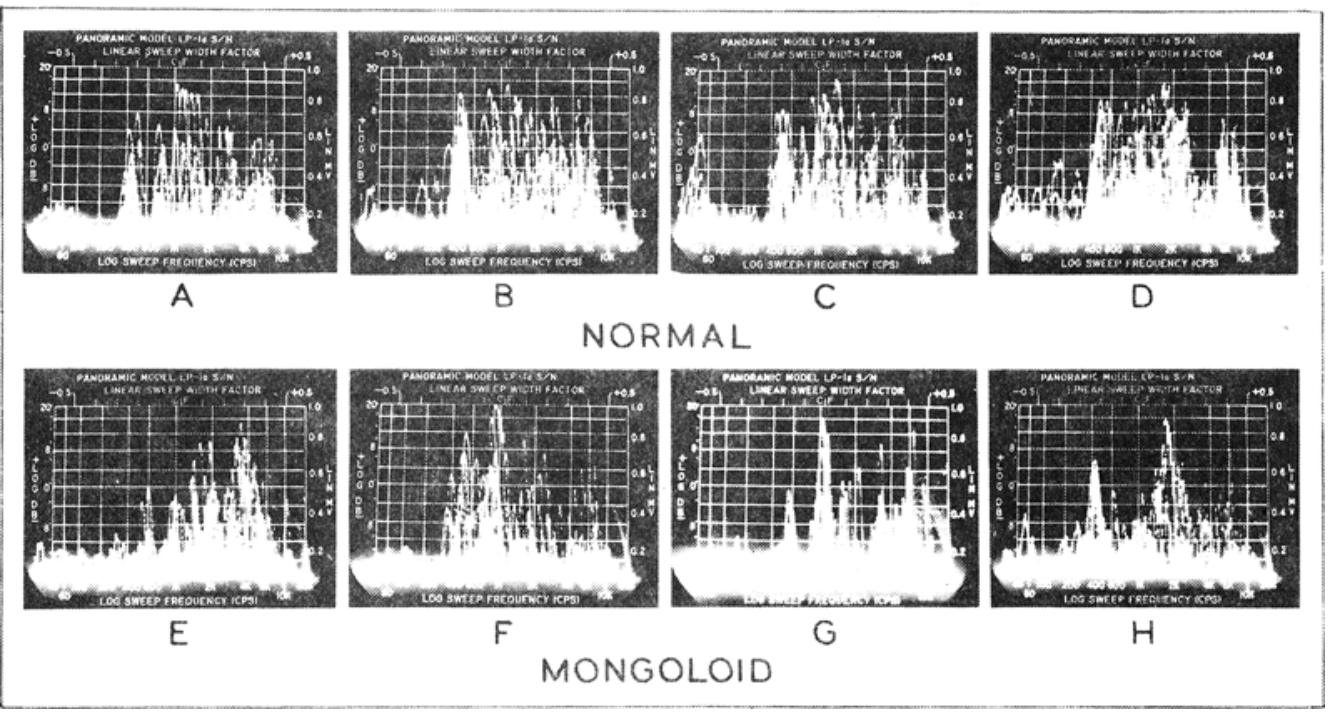




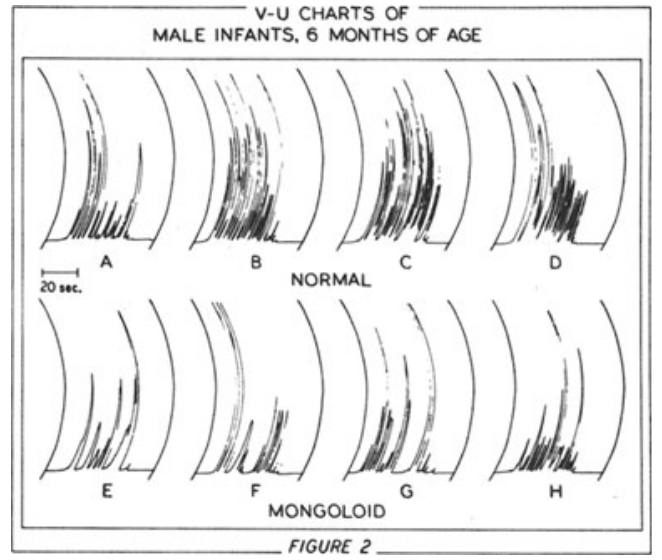

mal infants are relatively homogeneous in this respect. The spectra of the mongoloids show greater variability among themselves, and within each spectrogram more peaks and troughs are discernible indicating that intensity variations are much greater for the mongoloid than they are for the normal. The normal infants show much greater spectral activity for the same period of time than is found in the mongoloid spectrograms, thus the frequency (cps) content of the normal is much richer than it is for the mongoloid. When Volume Unit Charts were made for the identical cry samples shown in Fig. 1 they appear with corresponding letter identifications as in Fig. 2. In these charts, time is read from right to left and the pattern of crying is read without reference to frequency (cps). Intensity is shown on the ordinate from zero to five milliamps. These charts support the spectral data in terms of the greater activity levels for the cries of normal infants.

In addition the spectra shown in Fig. 1 reveal that while there are differences in activity and variability between the cries of normals and mongoloids, no clear lacunae in the spectral continuum a re indicated for either group. Thus individuals who have described the heard cry of one mongoloid infant as "gutteral" and of another mongoloid as "high pitched" probably were attending to one region of the spectrum, possibly the most active or loudest region for the particular infant. Notwithstanding other differences, the spectral range covered by the mongoloid's cry is the same as that of the cry of the normal infants. Another possibility is that the heard differences between cries of normal and mongoloid infants are principally timbral. Undoubtedly timbre differences help to differentiate one infant from another in either group.

The spectrograms indicated that the lower cps limit for all the spectra is somewhere in the range of 400 cps. Curves shown below $400 \mathrm{cps}$ are generally lower in intensity and probability represent noise from sources in the equipment used, both for recording and playback of the tapes. Much of the white haze seen along the base of all the spectra may be attributed to the same source.

\section{References}

Fisichelli, V. R., Karelitz, S., Eichbauer, J., \& Rosenfeld, L. Volume-unit graphs: Their production and applicability in studies of infants' cries. J. Psychol., 52, 423-1961.

Fisichelli, V. R., \& Karelitz, S. The cry latencies of normal infants and those with brain damage. J. Pediat., 1963, 62, 724-734.

Fisichelli, V. R., Coxe, H., Rosenfeld, L., Haber, A., Davis, J., $\&$ Karelitz, S. The phonetic content of the cries of normal infants and those with brain damage. J. Psychol., 1966, in press.

Karelitz, S., Karelitz, Ruth, \& Rosenfeld, L. Infants' vocalizations and their significance. In P. W. Bowman \& H. V. Mautner (Eds.), Mental retardation. Proc. First International Medical Conference, New York: Grune \& Stratton Inc., 1960. Pp. 439-446.

Karelitz, S., \& Fisichelli, V. R. The cry thresholds of normal infants and those with brain damage. J. Pediat., 1962.

Koenig, W., Dunn, H. K., \& Lacy, L. Y. The speech spectrograph. J. Acoust. Soc. Amer., 1946, 18, 1949.

Potter, R. K., Kopp, G. A., \& Green, H. C. Visible Speech. New York: D. Van Nostrand Co., 1947.

Winitz, H. Spectrographic investigation of infant vowels. J. genet. Psychol., 1960, 96, 171-181.

\section{Notes}

1. Supported by Grant No. HD-00332 of the National Institutes of Health, Division of Research Grants.

2. The authors are indebted to Messrs. J. Eichbauer and E. Feldman for their technical assistance and to Panoramic Radio of the Singer Corp. for the use of their facilities. 